\title{
CONCEPTS
}

\section{An Experience of Improvised Laryngoscopy}

\author{
Alison Matthews, MD, FAWM \\ From the University of Chicago, Chicago, IL; and the NorthShore University HealthSystem, Highland Park, IL.
}

\begin{abstract}
Airway management in the wilderness runs the gamut from basic airway support to endotracheal intubation. Fortunately, direct laryngoscopy is a seldom called upon skill in expedition medicine. However, the medical skills required during a mission or expedition are never truly known in advance. Improvisation during evolving medical events is a mainstay of expedition medicine education and practice. It is unlikely, given constraints of weight and size of expedition medical kits, that a conventional laryngoscope would find its way into a standard "go bag." Faced with the real but rare event of needing to intubate a patient in an austere environment, how can improvisation be used? Multiple ideas for improvised laryngoscopes can be found in the wilderness medicine literature, but which, if any, of these devices have true clinical utility? To this end, participants of a recent Wilderness Medical Society preconference in medical elements of light search and rescue were given the opportunity to devise and construct their own improvised laryngoscopes and attempt intubation of a training mannequin. Participants with varying degrees of intubating experience improvised effective laryngoscopes from provided materials and successfully intubated an airway mannequin.
\end{abstract}

Keywords: airway management, endotracheal intubation, laryngoscope, equipment design, wilderness medicine, expeditions

\section{Introduction}

Airway management skills in the wilderness range from simple supportive measures, such as a chin lift/jaw thrust maneuver, to intubation of the trachea. ${ }^{1-4}$ Between these 2 extremes are any number of airway techniques and devices, including oral airways, nasal airways, tongue traction, and extraglottic airways (i-gel, Combitube, King tube, laryngeal mask [LMA], intubating LMA). Although these airway interventions may be sufficient to improve oxygen exchange and carbon dioxide removal, they do not protect from aspiration of gastric contents. Placement of an endotracheal tube is the only way to provide a secure and controlled airway in a patient requiring ventilatory support. Endotracheal tubes can be placed blindly via a nasal approach, digitally with fingers palpating the glottic opening, under direct visualization using a laryngoscope, or via cricothyrotomy.

Direct laryngoscopy is a rarely called upon skill in expedition medicine. However, the anticipated goals of

Corresponding author: Alison Matthews, MD, FAWM, NorthShore University HealthSystem, 777 Park Avenue West, Highland Park, IL 60035; e-mail: amatthews1@uchicago.edu.

Submitted for publication October 2017.

Accepted for publication May 2018. the planned mission may evolve and change during execution. When responding to disaster situations it can be impossible to know in advance what equipment will be at one's disposal in the affected region. Practicing medicine in an austere environment, whether in a hospital setting in the developing world or during a disaster response with limited resources, requires flexibility of mindset and use of available resources. Necessity is oftentimes the mother of invention. Seeing common, ordinary objects in a new and unique light can be lifesaving. No matter the limitations of a given situation, our hands, our minds, and our improvisation skills are at our disposal wherever we are called to respond. Simulation-based training can be used to explore innovations, develop medical skills, and build confidence before actively practicing medicine in an austere environment.

\section{Background}

The first documented airway intervention was a tracheostomy dating back to the Bronze Age and described in the ancient Indian text Rig Veda. Subsequently, pioneering Egyptian physicians recorded use of surgical tracheostomy to relieve an upper airway obstruction. Greek 
and Roman literature of the early modern epoch reports additional instances of the life-saving use of tracheostomies. This knowledge of airway management was apparently "lost" in the intervening years and "rediscovered" during the Renaissance. During the 19th century, the unfortunately frequent circumstances of drowning and diphtheria led to a resurgence of these airway techniques being taught and utilized. This fascinating history was compiled by Szmuk et al in their article, "A brief history of tracheostomy and tracheal intubation, from the Bronze Age to the Space Age." 5

In a parallel fashion, during the late 19th century, the anesthetic world was evolving and developing nonsurgical airway interventions. Central among these innovations was direct laryngoscopy, a technique used to visualize the structures of the larynx. Most commonly, this procedure is used to facilitate endotracheal intubation, but it may also be used to evaluate the larynx for tumors, anatomy, foreign bodies, trauma, and nerve or structural injuries. The process of direct laryngoscopy was first published in $1895 .{ }^{6}$ However, endotracheal intubation was not detailed until $1913^{7}$ and was not commonly performed for surgical procedures until the mid-20th century. Further advancements by McGill, Macintosh, and Miller led to the laryngoscopes in common use today.

Informed by the progress in prehospital and combat casualty care, airway management in wilderness and expedition medicine has grown and developed. From basic supportive measures and mouth-to-mouth respiration, airway interventions in austere environments now include the full spectrum of care from the recovery position to surgical cricothyrotomy. Along with this advanced scope of practice, wilderness medicine practitioners have developed ways to improvise various airway adjuvants when necessary.

\section{Improvised airway management}

Airway management begins with the most basic interventions to assist and protect the patient's airway and ends with definitive airway control. Along this spectrum are any number of conservative measures before resorting to endotracheal intubation. The decision to move forward with intubation of the trachea is a major commitment to the patient and not to be made lightly. Once an endotracheal tube is placed, the patient will require 24-h support until definitive care is reached. This raises significant questions about the feasibility, duration, and difficulty of evacuation. Also to be considered is the ability of the team to meet these demanding evacuation requirements while ensuring the health and safety of the other team members. Before proceeding with intubation, consider if this is a realistic commitment.

With these caveats in place, a discussion of the various airway interventions that can assist with ventilation, oxygenation, and protection of a patient's airway can proceed. Included are techniques for improvising a range of devices, from the simplest to the most complex. If advanced airway management is warranted, several methods for intubation are described including an improvised endotracheal tube. Table 1 summarizes these techniques.

The most basic airway intervention is the recovery position. ${ }^{8}$ The patient is gently rolled to either the right or left lateral decubitus position with the dependent hand and forearm cradling the head. Provided the patient does not have a cervical spine injury, this is a safe position that helps maintain a patent airway and reduces risk of aspiration due to secretions or vomitus.

If the patient cannot be moved or airway obstruction continues, the next maneuver is a chin lift and jaw thrust. Care should be taken to maintain a neutral cervical spine with each of the actions. A chin lift is simply that: elevating the patient's chin by applying pressure below the chin and lifting slightly upward. This will have limited utility as the lifting action will soon begin to lead to cervical spine extension. Additionally, a jaw thrust can be used. The index and middle fingers are placed behind the angle of the mandible, and gentle traction distracts the mandible anteriorly. This can be achieved with little or no cervical extension. Maximum benefit of the jaw thrust maneuver is achieved once the lower incisors are displaced forward of the upper incisors (a profound underbite). ${ }^{9}$

If these interventions do not relieve the obstruction, a remedial airway intervention is the next step. Oral airways can be inserted to lift the tongue off the posterior oropharynx to relieve an airway obstruction. ${ }^{1}$ The $\mathrm{C}$-shaped device comes in various sizes. The appropriate size is determined by the distance from the corner of the mouth to the angle of the mandible. Using a tongue blade to depress the tongue, the airway is inserted following the curve of the tongue to the posterior oropharynx. Without a tongue depressor, the airway should be inserted with the tip pointing upwards toward the hard palate. The airway is inserted and slowly rotated 180 degrees following the curve of the tongue. A disadvantage of this intervention is that it can stimulate the airway reflexes of a conscious patient and cause vomiting and laryngospasm. Oral airways are more difficult to improvise as tubing can be compressed with biting, leading to secondary airway obstruction. Additionally, the tube needs to be secured to prevent 
Table 1. Airway management

\begin{tabular}{|c|c|c|c|c|}
\hline Airway intervention & Indications & Advantages & Disadvantages & Cautions \\
\hline Rescue position & $\begin{array}{l}\text { Helps maintain airway patency } \\
\text { and protect from possible } \\
\text { vomiting or bleeding into the } \\
\text { airway }\end{array}$ & Simple intervention & Does not support ventilation & $\begin{array}{l}\text { Observe for possible deterioration in } \\
\text { respiratory status }\end{array}$ \\
\hline Jaw thrust chin lift & $\begin{array}{l}\text { Oropharyngeal soft tissue } \\
\text { obstructing upper airway }\end{array}$ & Simple intervention & $\begin{array}{l}\text { May not improve overall gas } \\
\text { exchange }\end{array}$ & $\begin{array}{l}\text { Use care not to extend cervical spine } \\
\text { if possible injury }\end{array}$ \\
\hline Oral airway & $\begin{array}{l}\text { Obstruction in spontaneously } \\
\text { ventilating patient that does } \\
\text { not improve with jaw thrust }\end{array}$ & Simple intervention & $\begin{array}{l}\text { May not improve overall gas } \\
\text { exchange }\end{array}$ & $\begin{array}{l}\text { May provoke vomiting or } \\
\text { laryngospasm }\end{array}$ \\
\hline Nasal airway & $\begin{array}{l}\text { Patient too alert to tolerate oral } \\
\text { airway }\end{array}$ & Simple intervention & May cause epistaxis & $\begin{array}{l}\text { Do not use if midface fracture is } \\
\text { suspected }\end{array}$ \\
\hline Tongue traction & $\begin{array}{l}\text { Patient with soft tissue causing } \\
\text { airway obstruction }\end{array}$ & $\begin{array}{l}\text { Hands-free support of airway } \\
\text { patency }\end{array}$ & $\begin{array}{l}\text { Painful if patient regains } \\
\text { consciousness, bleeding }\end{array}$ & $\begin{array}{l}\text { Patient may still require jaw thrust } \\
\text { maneuver }\end{array}$ \\
\hline Bag mask ventilation & $\begin{array}{l}\text { Inadequate ventilation to } \\
\text { maintain gas exchange }\end{array}$ & $\begin{array}{l}\text { Does not require definitive } \\
\text { airway placement }\end{array}$ & $\begin{array}{l}\text { Technical skill that requires } \\
\text { practice }\end{array}$ & $\begin{array}{l}\text { Airway not protected from blood/ } \\
\text { vomit }\end{array}$ \\
\hline Supraglottic devices & $\begin{array}{l}\text { Assists ventilation and provides } \\
\text { oxygenation }\end{array}$ & $\begin{array}{l}\text { Does not require laryngoscopy or } \\
\text { surgical intervention }\end{array}$ & Does not protect from aspiration & $\begin{array}{l}\text { Difficult to provide high pressure } \\
\text { ventilation }\end{array}$ \\
\hline Nasal intubation & $\begin{array}{l}\text { Spontaneously ventilating patient } \\
\text { who requires ventilatory } \\
\text { support or airway protection }\end{array}$ & $\begin{array}{l}\text { Does not require direct } \\
\text { visualization of larynx to } \\
\text { secure airway }\end{array}$ & $\begin{array}{l}\text { Patient must be breathing } \\
\text { spontaneously }\end{array}$ & $\begin{array}{l}\text { Do not use if midface fracture is } \\
\text { suspected }\end{array}$ \\
\hline Oral intubation & $\begin{array}{l}\text { Obtunded patient who is not } \\
\text { breathing }\end{array}$ & $\begin{array}{l}\text { Provides secure, protected } \\
\text { airway and adequate gas } \\
\text { exchange }\end{array}$ & $\begin{array}{l}\text { Technical skill that requires } \\
\text { practice }\end{array}$ & $\begin{array}{l}\text { Maintain inline cervical stabilization } \\
\text { during laryngoscopy if cervical } \\
\text { spine injury suspected }\end{array}$ \\
\hline Needle cricothyrotomy & $\begin{array}{l}\text { Unable to ventilate patient via } \\
\text { bag mask or airway adjunct }\end{array}$ & $\begin{array}{l}\text { Provides the ability to deliver } \\
\text { oxygen }\end{array}$ & $\begin{array}{l}\text { Gas exchange may remain } \\
\text { inadequate }\end{array}$ & Does not provide airway protection \\
\hline Surgical cricothyrotomy & $\begin{array}{l}\text { Laryngoscopy difficult or } \\
\text { impossible }\end{array}$ & $\begin{array}{l}\text { Provides adequate gas exchange } \\
\text { with protected airway }\end{array}$ & $\begin{array}{l}\text { Technical skill that requires } \\
\text { practice }\end{array}$ & $\begin{array}{l}\text { May not be feasible if cricothyroid } \\
\text { membrane not identifiable due to } \\
\text { trauma or body habitus }\end{array}$ \\
\hline
\end{tabular}


aspiration into the posterior oropharynx. For these reasons, improvisation with a nasal airway is more feasible.

If the patient has an intact gag reflex but the airway is obstructed, the nasopharyngeal airway may be the more appropriate choice. ${ }^{1}$ The nasal "trumpet" is a beveled tube with a wide flange that prevents the tube from sliding into the posterior nasopharynx. The appropriate size will extend from the tip of the nose to the tragus. If available, topical vasoconstrictors can be sprayed in the nostrils before placement to minimize bleeding. It is best to start in the right naris because that is the most widely patent nostril for most patients. The direction of insertion is parallel to the roof of the mouth, not up into the nasal cavity. The tip of the bevel is inserted along the nasal septum to prevent the opening from impacting the turbinates. Although this device is less likely to instigate vomiting and laryngospasm, there is a risk of causing epistaxis. A nasal airway can be improvised using tubing with a safety pin affixed to the end to prevent it entering the airway.

Another maneuver to open a partially obstructed airway is tongue traction. ${ }^{1}$ With this intervention, 2 safety pins are inserted through the tip of the tongue. A string is passed through the safety pins and tied to buttons on the victim's shirt or jacket zipper. This traction pulls the tongue forward and off the posterior oropharynx to relieve the airway obstruction. Needless to say, this requires a patient who is quite obtunded and who may not be well pleased once consciousness is restored. Bleeding at the pin insertion sites is an additional concern and care needs to be taken to prevent this blood from entering the airway. This is an advantageous technique during transport because it is more difficult to dislodge than oral or nasal airways.

If these maneuvers fail to improve air exchange or the patient becomes obtunded to the point of apnea, assisted ventilation will be required. This can be provided by a resuscitation mask with one-way valve or using bag mask ventilation. ${ }^{1}$ During ventilation assistance, the mask is placed over the nose and mouth with the thumb on the nasal portion of the mask and the index and middle fingers on the lower portion of the mask. The little finger is then placed behind the angle of the mandible to provide a jaw thrust maneuver to help with opening the airway. With either technique, the minimum inflating pressure should be used to prevent gastric insufflation. Adequate ventilation can be confirmed by viewing chest rise. Supplemental oxygen is unlikely to be available on site, and it is valuable to remember that the exhaled breath of a mouth to mask rescuer will provide approximately $18 \%$ oxygen and a self-inflating bag will provide room air of $21 \%$ oxygen.
These oxygen percentages reflect sea-level values and will decrease with elevation gain.

If measures to this point have not improved the ventilatory status of the patient, more invasive interventions are required. ${ }^{10}$ The simplest next intervention will be an extraglottic airway. These include i-gels, LMAs, King tubes, and Combitubes. These are placed blindly and require minimal training and practice to achieve success. ${ }^{1}$ The latest Tactical Combat Casualty Care guidelines specifically recommend the i-gel device. ${ }^{11} \mathrm{It}$ must be remembered that these devices do not provide protection from aspiration of gastric contents. Some models have an additional port to suction gastric contents, but this does not prevent aspiration. Patients can be allowed to spontaneously ventilate or be supported by positive pressure ventilation. Blind intubation can be achieved through LMAs, but this requires more skill and training.

Blind nasal intubation is an airway intervention well worth learning. Nasal intubation lends itself to a "blind" approach due to the anatomy of the upper airway. An endotracheal tube emerging from the posterior nasopharynx has a "straight shot" down to the larynx. It is contraindicated in facial trauma where the cribriform plate may be disrupted. Like the nasal airway, epistaxis can occur during placement but is mitigated by using vasoconstrictors. Also, placement requires a spontaneously ventilating patient. The endotracheal tube is passed through the most patent naris. The tube is advanced while listening to breath sounds coming through the tube. If available, a Beck Airway Airflow Monitor may be used to amplify breath sounds to an audible whistle to guide placement. It is helpful to synchronize advancement of the tube with the inspiratory phase of the respiratory cycle. As the tube is advanced, breath sounds will increase in volume. If at any time breath sounds are lost, the tube should be pulled back slightly until breath sounds are heard again. When breath sounds are maximal, ask the patient to slowly take the deepest breath they can (this maintains open vocal cords). As the inspiration occurs, quickly advance the endotracheal tube. Coughing and breath sounds confirm tube placement. You now have a secured and patent airway that protects the airway and provides adequate oxygenation and ventilation.

If the patient is not spontaneously ventilating, the next intervention is an oral endotracheal tube. These can be placed digitally by palpating the glottic opening. Success will depend on prior experience and length of fingers. Some providers will realistically only be able to digitally intubate children. In contrast to blind nasal intubation, blind oral intubation is largely unsuccessful. Placement of oral endotracheal tubes therefore requires the use of a 


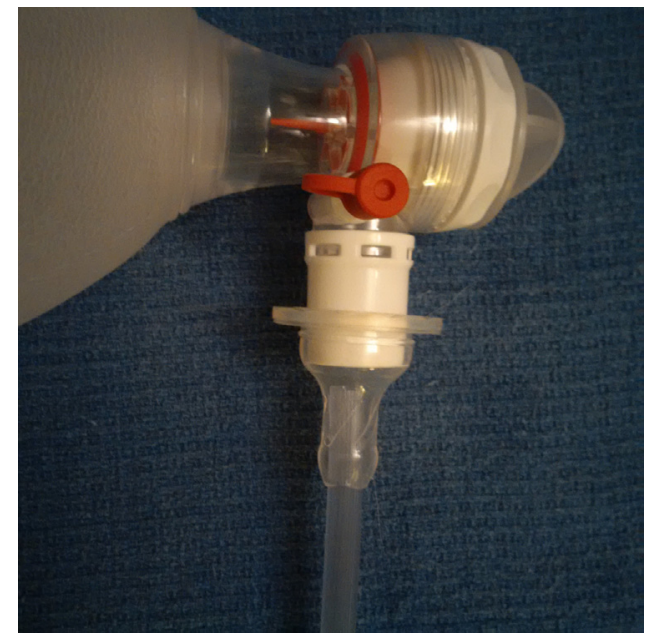

Figure 1. Baby bottle nipple adapter for endotracheal tube.

laryngoscope. A technique for improvised laryngoscopy is explained in detail in a later section. Endotracheal tubes (nasal and oral) can be improvised using almost any available tubing. Likely sources in the austere environment include personal hydration systems, solar shower hose, siphon tubing, and sports bottle straw. ${ }^{12,13}$ To overcome the lack of a tracheal cuff, the mouth can be packed to prevent an air leak. This is applicable to endotracheal tubes or cricothyrotomies. The only requirement for the oral packing is that it should be a continuous length of soft cloth: a neck gaiter, sock, sleeve, bandana, or portion of a t-shirt. The oral pack will not become a lost foreign body if it is 1 piece and a tail is kept visible emerging from the mouth. Oral packing does not prevent aspiration of gastric contents. To facilitate attaching the improvised endotracheal tube to a self-inflating bag, the tip of the tube can be inserted in a baby bottle nipple and attached to the bag (Figure 1). ${ }^{14}$

Last to be presented here are airways involving cricothyrotomy. In some instances, particularly military battlefield and civilian law enforcement tactical applications, this procedure may well be the initial airway intervention. ${ }^{15,16}$ It may also serve as a rescue technique when other airway interventions have failed. ${ }^{17,18}$ However, for most providers in the austere environment, cricothyrotomy will be a last resort. Several small, commercially available, tactical cricothyrotomy kits (North American Rescue, Tactical Medical Solutions, Portex, and H\&H solutions) are readily applicable to the austere medical environment. A previously described improvised needle cricothyrotomy device consists of an intravenous tubing drip chamber. ${ }^{19}$ Suggested here is a technique using a mini-spike dispensing pin ("Propofol spike") that maintains a large bore opening for oxygen flow but provides a more reliable and stable connection to a self-inflating bag. This improvised device uses a "Propofol spike" (Braun Medical reference number 412012), a $3 \mathrm{~mL}$ syringe, and a 7.0 endotracheal tube adaptor (Figure 2A and B). The spike is inserted into the cricothyroid membrane between the thyroid cartilage ("Adam's apple") and the cricoid cartilage. It can then be attached to a self-inflating bag device using the $3 \mathrm{~mL}$ syringe and the tube adaptor. For surgical cricothyrotomy, the same $3 \mathrm{~mL}$ syringe cut with an angled bevel can be inserted through the incised cricothyroid membrane. Other improvised surgical cricothyrotomies have been described using tubing from personal hydration systems and sports bottle straws. Contrary to depictions

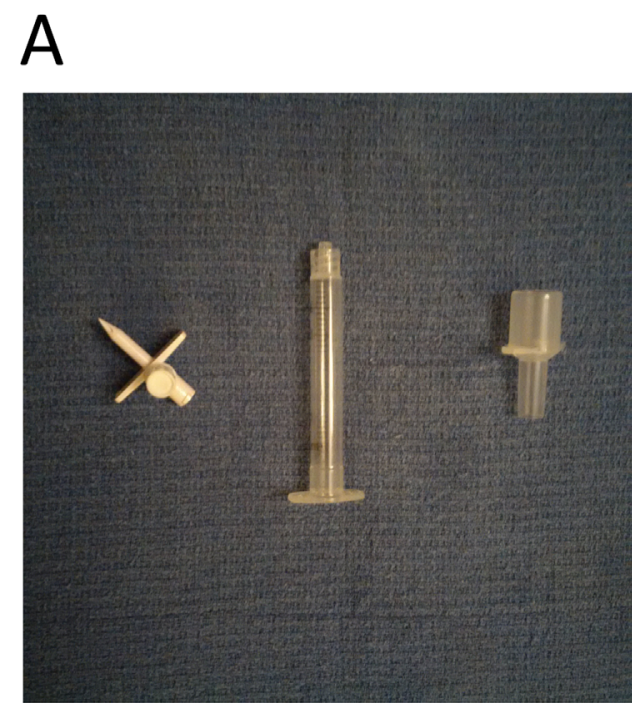

\section{B}

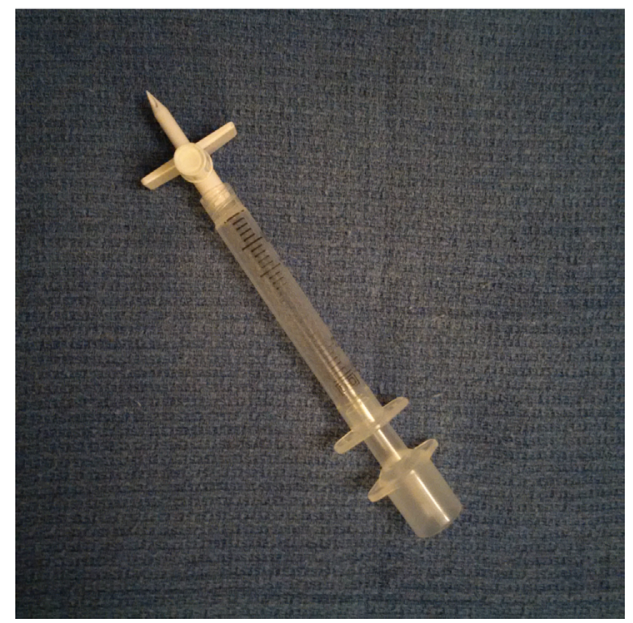

Figure 2. A, B, "Propofol spike," $3 \mathrm{~mL}$ syringe (barrel removed), and 7.0 endotracheal tube adapter. 
in popular media, most pens are not adequate for improvised cricothyrotomy.

Suction apparatus can be improvised using a wide mouth bottle, 2 lengths of tubing, and duct tape. Based on a DeLee suction trap, 2 holes are made in the lid of the bottle and the 2 tubes are inserted and duct taped in place. One tube is directed toward the patient and the other is inhaled through by the provider. This creates negative pressure within the bottle, which produces suction on the patient end to remove secretions. The jar serves as a reservoir to trap the suctioned fluids.

An improvised bag valve device has recently been described in the wilderness medicine literature. This was constructed of a Platypus personal hydration system and is described in detail by the authors. ${ }^{12}$

\section{Principles of laryngoscopy}

Laryngoscopy itself refers to visualization of the laryngeal structures. These include the vallecula, the epiglottis, the vocal cords, the arytenoid cartilages at the base of the vocal cords, and often an internal view of the trachea revealing its rings. Upon visualization of these structures, placement of an endotracheal tube provides an airway protected from the possibility of aspiration of gastric contents, provision for oxygenation, and ventilation of carbon dioxide. This is the gold standard of airway management: protection, oxygenation, and ventilation. The cuffed endotracheal tube can be placed via a variety of techniques (blind, palpation, direct visualization, or cricothyrotomy), but it is the only device that meets all these criteria.

\section{Technique of laryngoscopy}

The upper airway can be conceived of as having 3 different axes: the oral axis, the pharyngeal axis, and the laryngeal axis (Figure 3A). ${ }^{23}$ The classic "sniffing position" is achieved by elevating the occiput, which brings the external auditory canal in line with the plane of the sternum. In this orientation, the pharyngeal and laryngeal axes will align (Figure 3B). Direct laryngoscopy is then required to align the oral axis and obtain a direct view of the larynx (Figure 3C). With the larynx directly in view, the endotracheal tube can be passed between the vocal cords, resulting in patent, protected, and secure airway.

Conventional laryngoscopes consist of a battery compartment that serves as a handle to which the desired blade is attached (Figure 4). Laryngoscope blades can be either curved or straight. Miller blades are the most commonly used straight blades. They are used to lift the epiglottis directly to expose the vocal cords. Macintosh (MAC) blades are the most commonly available curved
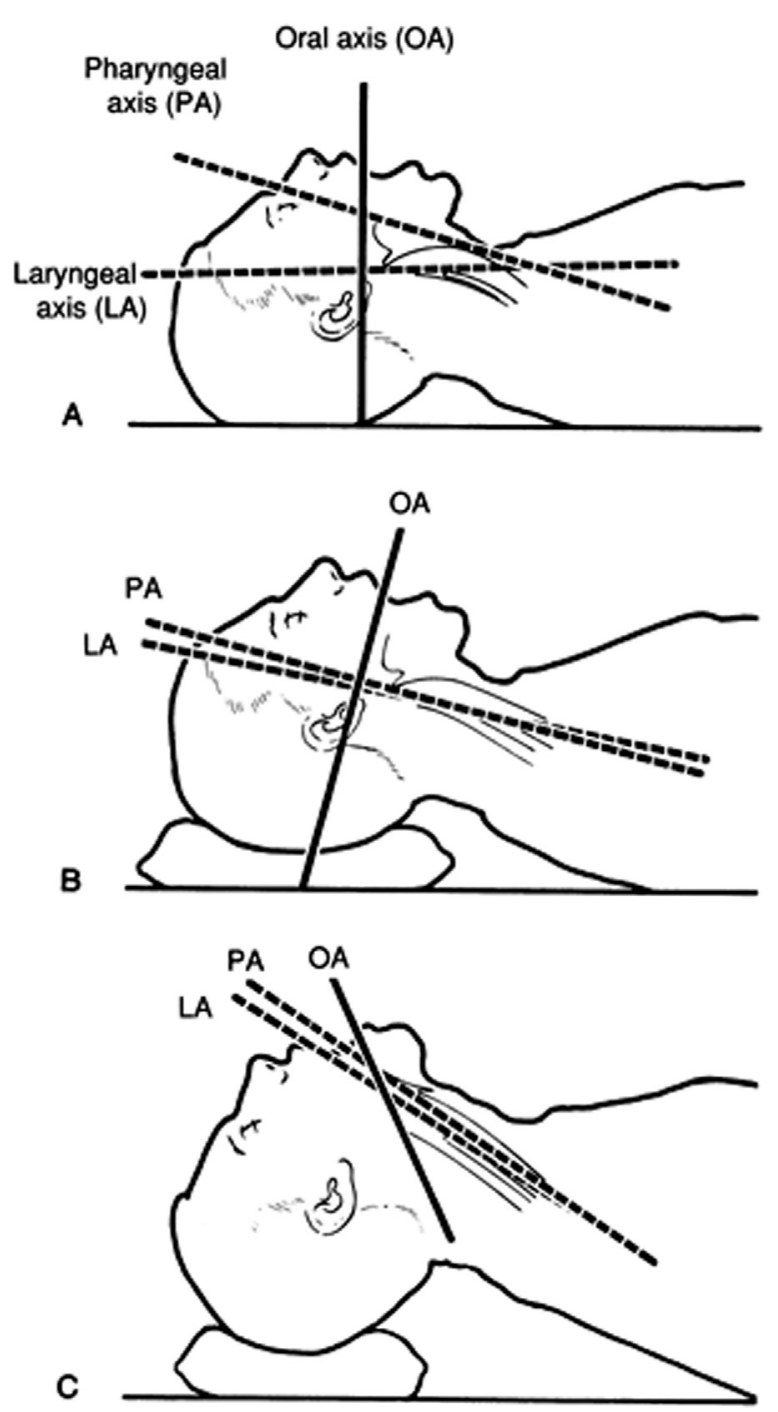

Figure 3. A, Axes of the airway. B, Classic "sniffing" position with pharyngeal axis and oral axis aligned. $\mathrm{C}$, Laryngoscopic view bringing laryngeal axis into alignment.

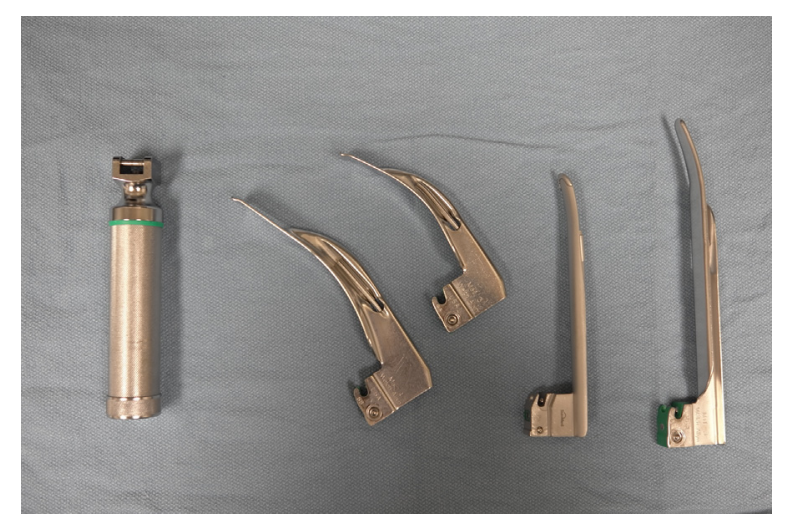

Figure 4. Conventional laryngoscopes, from left: laryngoscope handle, MAC 4, MAC 3, Miller 2, Miller 3. 
blades. The tip of the curved MAC blade is placed in the vallecula (anterior to the epiglottis) and the epiglottis is distracted upwards without direct contact. User skill and preference usually determines the type of blade that is used. However, in patients with small mouths or prominent incisors, narrow straight blades may be more effective. For the patient with a large tongue, the larger Mac blade is better able to displace the tongue from the line of sight of the laryngoscopist.

\section{Improvised laryngoscopy}

With this understanding of the anatomy of the upper airway and the principles of direct visualization of the larynx, improvised devices can be designed. The ideal improvised laryngoscope would be wide enough to compress or move the tongue, be of appropriate length to displace the epiglottis, be free of sharp or rough edges to protect the teeth and soft tissue from injury, have a source of illumination (intrinsic or extrinsic) to provide a view of the vocal cords, and have a comfortable handle. Some improvised laryngoscopes that have been suggested include bent spoons,${ }^{24}$ aluminum flanges, ${ }^{25,26}$ or other handmade devices. ${ }^{27}$

At the annual meeting of the Wilderness Medical Society in Breckenridge, Colorado, in July 2017, a preconference workshop in medical elements of light search and rescue was presented with improvised airway management as one component of the workshop. The preconference workshop focused on components of search and rescue techniques, including locating casualties, stabilizing patients, determining evacuation route, preparing for evacuation, and transport to definitive care. A main component of the workshop was workstations. At the airway station, students were encouraged to build and design laryngoscopes with supplied items. Participants at the workshop had varying degrees of experience with laryngoscopy and intubation. None had prior

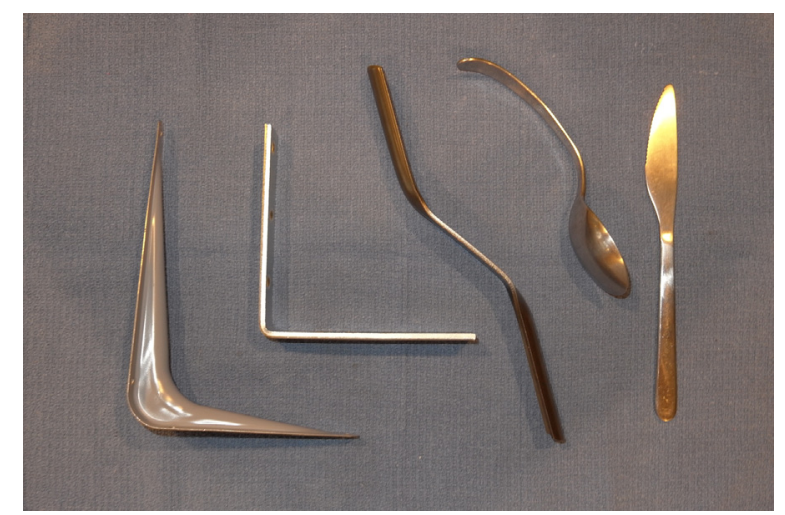

Figure 5. Improvisation objects from left: shelf support, wall bracket, concrete spreader, bent spoon, knife.

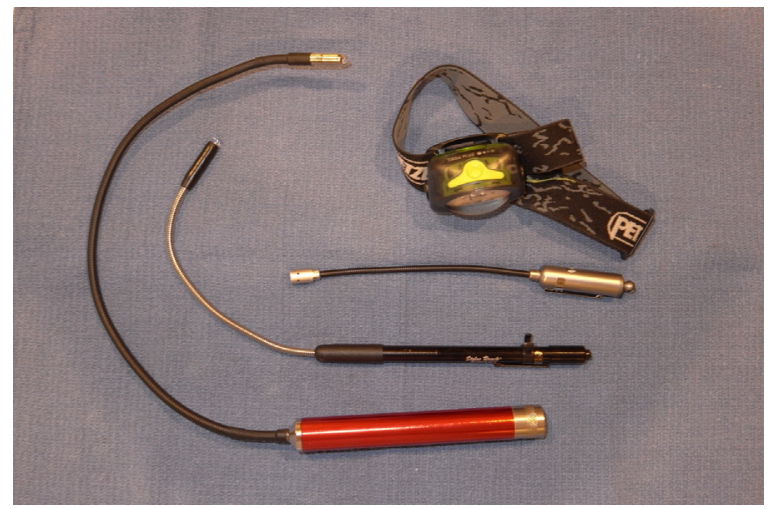

Figure 6. Improvised light sources.

experience of using an improvised intubating device. They had access to a variety of items that simulate objects carried on expeditions (eating utensils) or might be found at disaster scenes. These objects included knives, spoons, metal brackets, metal corner bars, and metal handles (Figure 5). Light sources available consisted of light wands, a headlamp, and flexible light-emitting diode flashlights (Figure 6). Using trial and error, participants constructed a variety of improvised devices with and without integrated light sources and attempted intubation of an Ambu intubation mannequin (Figure 7). This model has a "cut away profile" that is beneficial for instructing students on placement of airway devices. Students were able to directly visualize whether the airway device was being inserted properly and adjust their technique as warranted. A disadvantage of the sagittal split was that it was impossible to demonstrate positive pressure ventilation, and extraglottic devices did not seat well. Additionally, the stiff soft tissue structures and unrealistic larynx limited its usefulness as a true surrogate for intubation.

The improvised devices most conducive to successful laryngoscopy and intubation consisted of a nonmalleable device bent at 90 degrees with an integrated light source.

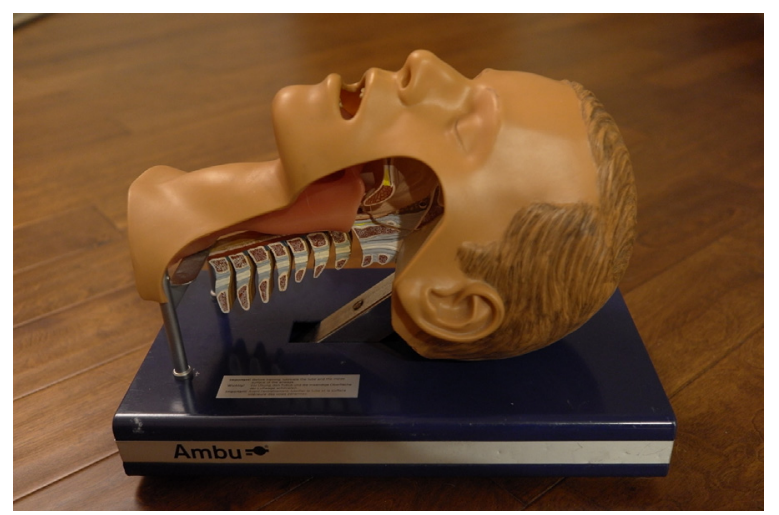

Figure 7. Ambu brand intubating mannequin. 


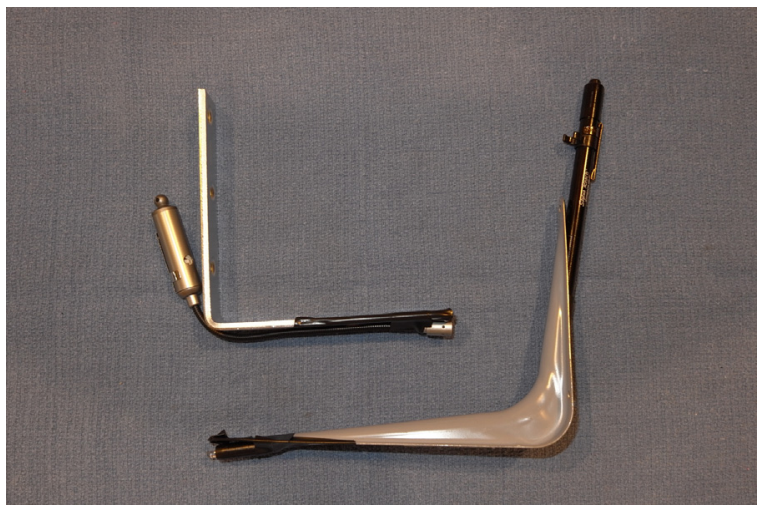

Figure 8. Successful improvised laryngoscopes.

These were constructed from an angle bracket and a shelf support with a light wand attached as a light source (Figure 8). Curved and straight blades were both effective. Although both successful improvised devices used integral light sources, selection of the light source was not critical to success of the device. Without an integrated light source, a standard headlamp was effective for illuminating the vocal cords, provided it was placed low along the bridge of the nose in the line of sight and not on the forehead. Alternatively, an assistant holding a light source over the right shoulder of the laryngoscopist could also assist in illuminating the larynx. Transillumination of the cricothyroid membrane to guide endotracheal tube placement has been described $^{2}$ but was not feasible in the opaque intubating mannequin used. Historically, sunlight was used during the very early days of laryngoscopy and only required appropriate patient positioning to allow direct sunlight to illuminate the patient's larynx. ${ }^{6}$ However, this was not attempted during the workshop. Some participants successfully intubated with straight objects, such as a dull knife, but success was limited by upper body strength.

The 2 improvised laryngoscopes represented in Figure 8 were the most reliable designs. Participants using one of these devices were able to successfully intubate the mannequin. An intubation was deemed successful if the participant could place the endotracheal tube into the trachea of the mannequin, regardless of time or number of attempts. These findings are limited to observations during a single workshop. Therefore, further investigation is warranted using a controlled study environment to evaluate success rates based on participant's level of experience, time to insertion, and number of attempts between the various improvised devices. Additionally, a cadaver study would be worthwhile to evaluate for possible evidence of airway trauma related to these devices and to
Table 2. Suggested items for an austere environment airway kit

Unsupported expedition (weight just under $16 \mathrm{oz}$ )

Pulse oximeter (fingertip)

Resuscitation mask with one-way valve

Oral airways $80 \mathrm{~mm}, 90 \mathrm{~mm}$

Nasal airway $7.0 \mathrm{~mm}, 7.5 \mathrm{~mm}, 8.0 \mathrm{~mm}$

i-gel LMA size 4

7.0 endotracheal tube

$3 \mathrm{~mL}$ syringe

Propofol spike

Chlorhexidine prep stick

Scalpel

Bulb syringe

Lubricant

Gloves

Phenylephrine nasal spray

Supported expedition (above items with the addition of):

Nasal cannula

i-gel LMAs size 3 and 5

Laryngoscope handle with MAC 3 and Miller 2 blades

6.0, 6.5, and 7.5 endotracheal tube

Endotracheal tube stylet

Bougie

Commercial cricothyrotomy kit

Oxygen cylinder

Bag valve device with mask

Colorimetric carbon dioxide indicator

Portable foot pump suction apparatus

LMA, laryngeal mask.

determine transferability of mannequin data to human airways.

\section{Austere environment airway management kit}

Table 2 presents suggested items for an austere environment airway kit. Two kits are described, 1 for short-term missions with small teams and 1 for longer expeditions. Either of these kits, augmented by the previously discussed improvisation methods, will be valuable equipment for the expedition medic.

\section{Conclusions}

Participants with differing levels of airway management skills were able to successfully intubate a mannequin simulator using self-created improvised laryngoscopes. These devices were constructed by the participants using a selection of available items that simulated objects that might be found on expeditions or in disaster situations. One device simulated a previously described improvised laryngoscope (the spoon), ${ }^{22}$ but the rest were designs unique 
to the workshop. When conventional laryngoscopes are unavailable in austere environments, improvised laryngoscopes are effective alternatives to facilitate intubation of the trachea. Allowing inexperienced laryngoscopists the opportunity to devise and fashion improvised laryngoscopes and then use these devices to intubate a training mannequin can be an important method to build improvisational medical skills.

Acknowledgments: The author acknowledges the Wilderness Medical Society and Nick Williams, DO for the opportunity to present at the preconference workshop of the annual meeting in Breckenridge in 2017.

Author Contributions: Concept, design, manuscript, and photographs (AM)

Financial/Material Support: None.

Disclosures: None.

\section{References}

1. Mahadevan S. Emergency airway management. In: Auerbach PS, ed. Wilderness Medicine. 6th ed. Philadelphia, PA: Mosby; 2012:392-410.

2. Ayim EN. Controlled ventilation and intubation. Primary Anaesthesia. 1st ed. New York: Oxford University Press; 1986:95-107.

3. Iserson KV. Airway. In: Improvised Medicine: Providing Care in Extreme Environments. 2nd ed. New York: McGraw-Hill Education / Medical; 2016:102-34.

4. Auerbach PS. Emergency airway management. In: Field Guide to Wilderness Medicine. 3rd ed. Philadelphia, PA: Mosby, Elsevier; 2008:78-97.

5. Szmuk P, Ezri T, Evron S, Roth Y, Katz J. A brief history of tracheostomy and tracheal intubation, from the Bronze Age to the Space Age. Intensive Care Med. 2008;34(2):222-8.

6. Hirsch NP, Smith GB, Hirsch PO. Alfred Kirstein. Anaesthesia. 1986;41(1):42-5.

7. Jackson C. The technique of insertion of intratracheal insufflation tubes. Surg Gynecol Obstet. 1913;17:507-9.

8. Dallimore J. Emergencies: collapse and serious illness. In: Johnson C, ed. Oxford Handbook of Expedition and Wilderness Medicine. 2nd ed. Oxford, UK: Oxford University Press; 2015:227.

9. Dallimore J. Airway. In: Oxford Handbook of Expedition and Wilderness Medicine. 2nd ed. Oxford, UK: Oxford University Press; 2015:186.

10. Rogers IR. The laryngeal mask airway-another technique for failed airway management under adverse conditions. Wilderness Environ Med. 1999;10(4):275-6.
11. Otten EJ, Montgomery HR, Butler FK Jr. Extraglottic airways in tactical combat casualty care: TCCC guidelines change 17-01 28 August 2017. J Spec Oper Med. 2017;17 (4):19-28.

12. Johnson CA, Goodwine DS, Passier I. Improvised cricothyrotomy on a mountain using hiking gear. Wilderness Environ Med. 2016;27(4):500-3.

13. Adams BD, Whitlock WL, Adams BD, Whitlock WL. Bystander cricothyroidotomy performed with an improvised airway. Mil Med. 2002;167(1):76-8.

14. Albert SNA. "Homemade" endotracheal-tube adaptor. Anesth Analg. 1973;52(1):79.

15. Mabry RL, Kharod CU, Bennett BL. Awake cricothyrotomy: a novel approach to the surgical airway in the tactical setting. Wilderness Environ Med. 2017;28(2). S61-S61.

16. Keller MW, Han PP, Galarneau MR, Brigger MT. Airway management in severe combat maxillofacial trauma. Otolaryngol Head Neck Surg. 2015;153(4):532-7.

17. Wharton DR, Bennett BL. Surgical cricothyrotomy in the wilderness: a case report. Wilderness Environ Med. 2013;24(1):12-4.

18. Shannon NJ, Shannon GD. "Blind" emergency cricothyrotomy in patients with complicating factors under adverse conditions. Wilderness Environ Med. 1998;9(4):260-1.

19. Platts-Mills TF, Lewin MR, Wells J, Bickler P. Improvised cricothyrotomy provides reliable airway access in an unembalmed human cadaver model. Wilderness Environ Med. 2006;17(2):81-6.

20. Kisser U, Braun C, Huber A, Stelter K. Bystander cricothyrotomy with ballpoint pen: a fresh cadaveric feasibility study. Emerg Med J. 2016;33(8):553.

21. Owens D, Greenwood B, Galley A, Tomkinson A, Woolley S. Airflow efficacy of ballpoint pen tubes: a consideration for use in bystander cricothyrotomy. Emergy Med J. 2010;27(4):317-20.

22. Hessert MJ, Bennett BL. Optimizing emergent surgical cricothyrotomy for use in austere environments. Wilderness Environ Med. 2013;24(1):53-66.

23. Stone DJ, Gal TJ. Airway management. In: Miller's Anesthesia. 5th ed. Philadelphia, PA: Elsevier Churchill Livingstone; 2005:1419.

24. Bewes P. Controlled ventilation and intubation. Primary Anaesthesia. Oxford Medical Publications; 1986:102.

25. Gillett GB, Patkin M. A laryngoscope for emergency use. Anaesthesia. 1964;19(4):595-7.

26. The Staff of the CMC Hospital Vellore, The Vellore laryngoscope. J Christ Med Assoc India. 1965;40:459.

27. O'Donohoe BP, Page RJE, Awini C. Where there is no laryngoscope. Anaesthesia. 1988;43(11):970-1. 